\title{
BENEFAKTIVNI KAUZATIV I NORVEŠKI FÅ-PASIV
}

Predmet rada je benefaktivni kauzativ, koji kao podtip indirektne kauzacije podrazumeva minimalno dva učesnika kauzativne situacije, kauzatora koji inicira radnju i kauzanta koji pod uticajem uzročnika sprovodi subordiniranu radnju do postizanja rezultata. Ipak, benefaktivni kauzativ se odlikuje nekolikim specifičnostima, kao što su pridruženje komponente benefaktivnosti agentivnom kauzatoru radnje, čime aficirani kauzator snižava svoju prototipičnost, te formalnim neizražavanjem semantički impliciranog kauzanta, čime se dvoaktantska struktura predstavlja kao situacija sa jednim učesnikom. U radu se ispituje korelacija između semantike benefaktivne kauzacije i jednog načina njenog formalnog kodiranja u norveškom jeziku, verbalnog kompleksa koji je tradicionalno prepoznat pod nazivom fă-pasiv. Jedan od glavnih ciljeva rada je analiza kontinuuma benefaktivnih i/ili kauzativnih

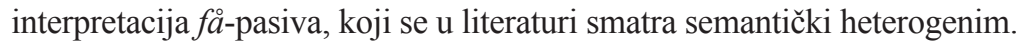

Ključne reči: benefaktivni kauzativ, kauzativna situacija, få-pasiv, indirektna kauzacija, kauzant, aficiranost, norveški jezik.

\section{Uvod}

Tema ovog rada je semantička analiza posebnog tipa indirektne kauzacije, benefaktivnog kauzativa, onako kako se iskazuje u norveškom jeziku putem verbalnog kompleksa poznatog pod nazivom 'fä-pasiv'. Cilj rada je višestruk. S jedne strane nam je svakako cilj da doprinesemo rasvetljavanju semantike benefaktivne kauzacije, kao i popularizaciji ovog termina koji u lingvističkoj literaturi nije doživeo širu rasprostranjenost. S druge strane, cilj rada je uspostavljanje korelacije između značenjskih aspekata benefaktivne kauzacije i jednog načina njenog formalnog izražavanja $u$ norveškom jeziku, čime konstrukcija få-pasiva postaje jedan od mogućih podtipova analitičkih kauzativnih konstrukcija u norveškom jeziku. Osim toga, cilj rada je da se putem analize semantičkih komponenata koje karakterišu učesnike ove kauzativne situacije razjasni kontinuum benefaktivnih i/ili kauzativnih interpretacija koje povezuju različite instance $f a$-pasiva, koje se tradicionalno u gramatičkoj literaturi smatraju heterogenima. 


\section{Benefaktivni kauzativ}

Termin benefaktivni kauzativ nije široko rasprostranjen u lingvističkoj literaturi, a i samoj u kauzativistici, u čijem je fokusu već decenijama semantička analiza tipova kauzacije ova problematika u velikoj meri ostaje neprepoznata i zanemarena. Termin benefaktivni kauzativ preuzet je iz Babby (1993), i pod njim podrazumevamo posebne instance kodiranja indirektne kauzativne situacije u kojoj je kauzator istovremeno i inicijator radnje i beneficijens ${ }^{1}$, ali ne i izvršilac date radnje, pri čemu pravi izvršilac, tj. učesnik sa ulogom kauzanta-posrednika ostaje površinski nerealizovan, kao u primeru:

(1) Jeg fikk sydd inn en dress. 'Dao sam da mi se suzi odelo'

Ovako određen benefaktivni kauzativ zauzima posebno mesto kako u semantičkom sistemu različitih podtipova indirektne kauzacije, tako i u formalnom sistemu analitičkih kauzativnih konstrukcija.

\subsection{Benefaktivni kauzativ kao tip indirektne kauzacije}

Svaka kauzativna situacija (u daljem tekstu: KS) se tradicionalno shvata kao makrosituacija koju čine minimalno dva poddogađaja ili mikrosituacije povezana odnosom kauzacije (up. Frawley, 1992). Prvi poddogađaj nazivamo uzročnim događajem (u daljem tekstu: $\mathrm{S}_{1}$ ) i on predstavlja predikacija uzroka, dok se drugi poddogađa naziva uzrokovanim događajem ili rezultatom (u daljem tekstu: $\mathrm{S}_{2}$ ) do kog je dovela $\mathrm{S}_{1}$. Prototipičnim

1 Radnja se ne mora nužno odvijati u korist agensa; ukoliko se odvija na njegovu štetu, tako da je on zapravo maleficijens radnje, takvu konstrukciju možemo nazivati adverzivnim kauzativom, po analogiji sa terminom adverzivni pasiv (eng. adversity passive), up. Babby (1993), Pylkkänen (2000). Za potrebe ovog rada je dovoljno koristiti termin benefaktivni kauzativ kao širi pojam. Kao prvo, sama konstrukcija u norveškom jeziku ne pokazuje da li je učesnik pozitivno ili negativno aficiran, već to zavisi od semantike glagolske lekseme ili, pak, od šireg diskursnog konteksta. Kao drugo, tipološke studije (up. Radetzky \& Smith 2010:98) ukazuju na to da IE jezici iz semantičke perspektive kodiraju i benefaktivna i malefaktivna značenja u okvirima jedne superkonstrukcije (eng. affectedness construction), koja između ostalog može da obuhvati i dativne i aplikativne konstrukcije. 
modelom KS smatraju se instance direktne nemedijativne kauzacije, tj. prototipične tranzitivne situacije sa minimalno dva odeljena učesnika u kojoj voljni agens u ulozi kauzatora deluje svesno i namerno, usmeravajući svoju aktivnost ka pacijensu, čijom se promenom (fizičkog) stanja kompletira kauzativni događaj (Croft, 1998; Rawoens, 2007).

Nasuprot tome, pod indirektnom kauzacijom se tradicionalno podrazumeva medijativna kauzacija, ona KS u kojoj se kauzator ne može pojmiti kao kauzator-efektor, dakle, učesnik koji inicira i sprovodi događaj od početka do kraja, već se $S_{2}$ sprovodi posredno, preko kakvog drugog entiteta ili procesa koji je neposredni izvor energije u postizanju rezultata (up. i Kemmer \& Verhagen, 1994: 120; Verhagen \& Kemmer, 1997: 67; Shibatani \& Pardeshi, 2001: 139-140; Rawoens, 2007: 88-89). Prototipična indirektna kauzacija se dominantno izjednačava sa situacijom u kojoj učestvuju dva konceptualno, semantički i formalno odeljena agentivna učesnika, pri čemu se oba pojavljuju kao manje prototipični agentivni učesnici jer se kauzator celokupne kauzativne makrosituacije izjednačava sa kauzatorom-inicijatorom, dok je agens $\mathrm{S}_{2}$ zapravo agens-realizator u ulozi kauzanta (u literaturi poznatiji pod engleskim nazivom causee):

(2) Legen fikk meg til å hoste. 'Lekar me je naterao da se nakašljem'

Osnovnim semantičkim parametrima uloge kauzant smatraju se voljnost (sposobnost učesnika da voljno/nevoljno obavi radnju koju je inicirao kauzator), parcijalna aficiranost (činjenica da čin kauzacije može direktno uticati na kauzanta koji time biva aficiran u manjoj ili većoj meri, čime može biti i agentivnog i pacijentivnog karaktera), te nedostatak komponente iniciranja radnje (up. Næss, 2007: 89). To je učesnik koji je dobrovoljno i svesno uključen u radnju koja ga pogađa, a posrednost uticaja, aficiranost kauzanta i stepen kontrole koju zadržava nikada nisu izolovane vrednosti, već se tumače prvenstveno u saodnosu sa stepenom kontrole koju vrši kauzator.

Za razliku od prototipičnih instanci indirektne kauzacije, benefaktivni kauzativ KS predstavlja kao indirektnu, uz implikaciju kauzanta-posrednika koji se, pak, na formalnom planu ne realizuje, dok se istovremeno inicijatoru radnje pridružuje jasna semantička komponenta benefaktivnosti, čime se na poziciji subjekta realizuje netipični, aficirani agens. 


\subsection{Izražavanje benefaktivnog kauzativa u norveškom jeziku}

Semantika benefaktivne kauzacije se u norveškom jeziku se osim få-pasivom može iskazati i kontekstualnim kauzativima, kao i analitičkim kauzativnim konstrukcijama sa glagolom la. Pod kontekstualnim kodiranjem se podrazumevaju tranzitivne konstrukcije koje ne sadrže formalne pokazatelje kauzativnosti, a konstrukcije se u zavisnosti od konteksta mogu tumačiti tranzitivno/prosto kauzativno ili hibridno kauzativno:

$$
\text { Jeg har reparert bilen.'Popravio sam auto' }
$$

Ukoliko je reč o tranzitivnom ili prostom kauzativnom tumačenju, učesnik na poziciji subjekta je agens celokupne radnje popravljanja automobila (inicijator i realizator), dok hibridno kauzativno tumačenje podrazumeva da je učesnik na poziciji subjekta samo inicijator radnje koju je za njega/u njegovu korist obavio drugi učesnik (automehaničar), a tumačenje se naziva hibridnim jer se situacija sa dva učesnika formalno kodira kao situacija sa jednim učesnikom.

Iako se u norveškom jeziku mnoge tranzitivne konstrukcije mogu dvojako tumačiti', kao na primer: sjekke øynene ('proveriti oči'), reparere bilen ('popraviti auto') ili gi ut en bok ('izdati knjigu'), podaci pokazuju da su daleko frekventnije kauzativne parafraze tradicionalno poznate pod nazivom 'få-pasiv': få sjekket øynene, få reparert bilen, få boka utgitt.

Na samoj periferiji se nalaze konstrukcije sa permisivnim kauzativnim glagolom la ('pustiti') i infinitivskom dopunom, koje se iz sistema permisivnih kauzativnih konstrukcija (primer 4a) izdvajaju po tome što učesnik na poziciji direktnog objekta može biti subjekat isljučivo u pasivnoj rečenici (primer 4b):

2 Tek u konstrastivnim istraživanjima postaje očiglednije da jezici u različitom stepenu dopuštaju kontekstualno kodiranje kauzativnosti, te se mnogi kontekstualni kauzativi jednog jezika ne mogu tumačiti hibridno kauzativno u drugom jeziku. Tako se ekvivalenti tranzitivnih konstrukcija tipa 'sašiti haljinu' ili 'promeniti ulje na kolima', koje u srpskom jeziku dozvoljavaju oba tumačenja, u norveškom jeziku mogu interpretirati isključivo prosto kauzativno, pri čemu se na poziciji subjekta kodira samo agens koji inicira i sprovodi radnju. Mogućnost hibridnog kauzativnog tumačenja postoji ukoliko se uz tranzitivnu konstrukciju javlja odredba koja označava vršioca radnje ili mesto vršenja radnje: Da jeg skiftet olje hos Mazda-forhandleren, fikk jeg bekreftet to ganger at de skulle ringe med en gang de var ferdige ('Kada sam menjao ulje u Mazdinom servisu, dvaput su mi potvrdili da će nazvati čim budu završili'). 
(4) a. Vi lot dem gå. 'Pustili smo ih da odu' $\rightarrow$ De gikk. 'Otišli su' b. Kongen lot ham dømme og henrette. 'Kralj je dao da ga osude i smaknu' $\rightarrow$ Han ble dømt og henrettet. 'Bio je osuđen i smaknut'

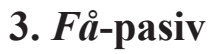

' $F a ̊$-pasiv' je verbalni kompleks koji se sastoji od glagola $f a ̊$ ('dobiti') koji se može menjati u kategoriji tempusa i participa perfekta glavnog glagola (otuda i naziv koji ukazuje na strukturnu povezanost sa perifrastičnom pasivnom konstrukcijom). Ova konstrukcija semantički nije jednoznačna, i na osnovu Faarlund et al. (1997: 658-659) mogu se izdvojiti četiri glavne interpretacije:

a. Vi fikk ordnet telefonen. 'Sredili smo telefon/Uspeli smo da sredimo telefon'

b.Hunfikkinnvilgetlånet/Hunfikklånetinnvilget.'Odobren joj je kredit'

c. Jeg fikk sterilisert hunnkatten min på lørdag. 'Sterilisao sam mačku u subotu'

d. Familien fikk alt odelagt av flommen. 'Porodici je sve uništeno u poplavi'

Interpretacija koja je ilustrovana primerom (5a) izdvaja se od preostale tri time što se može tumačiti kao rezultativna aspekatska konstrukcija (Faarlund et al., 1997: 658), i deo je šireg spektra konstrukcija u kojima se glagol $f a ̊$ javlja kao pomoćni glagol u aspektualnim značenjima. ${ }^{3} \mathrm{U}$ fokusu je rezultat radnje označene glavnim glagolom, tako što se izražava radnja koju je učesnik na poziciji subjekta uspeo da dovrši ili obavi. Lødrup

3 U aspektualnim značenjima se glagol få može pojaviti i u ingresivnim i u rezultativnim aspektualnim konstrukcijama. On označava primarno iznenadnu ili slučajnu ingresivnost, i to najčešće u kombinaciji sa kakvim glagolom kognicije ili čulne percepcije kao glavnim: Vi fikk vite det av leereren ('Saznali smo to od nastavnika') ili Ved en tilfeldighet fikk hun høre om bryllupet ('Sasvim slučajno je čula za svadbu'). U rezultativnim konstrukcijama se značenje glagola få kao pomoćnog vezuje za značenje postignuća, i on se tada pojavljuje u konstrukcijama sa obaveznom dopunom u vidu infinitiva ili participa perfekta: Han fikk sende/sendt telegram til sine noermeste ('Uspeo je da pošalje telegram svojim najbližima'). 
(1996:76) ovo naziva aktivnim få jer je subjekat ovih rečenica agens celokupne radnje, dok bi se za preostale tri grupe mogao primeniti njegov termin pasivnog $f a{ }^{4}{ }^{4}$

Primeri (5b), (5c) i (5d) mogu se interpretirati kao veoma srodni na semantičkom kontinuumu koji primarno odlikuje zajednička komponenta benefaktivnosti. Primer (5b) nazivamo recipijentskom konstrukcijom sa glagolom $f a ̊$ i može se posmatrati kao konstrukcija koja odgovara recipijentskom pasivu ${ }^{5}$, a učesnik na mestu subjekta se u nemarkiranoj pasivnoj parafrazi može pojaviti u obliku predloške sintagme: Boka ble sendt til oss. ${ }^{6}$ Interpretacije kao u primerima (5c) i (5d) su u Faarlund et al. (1997:849) kvalifikovane kao dve semantički različite konstrukcije na osnovu toga koji je tip učesnika kodiran na poziciji subjekta: smatraju da je u primeru (5d) reč o posesivnom konstituentu, dok je u primeru (5c) na mestu subjekta agentivni učesnik. Konstrukcije kao u primeru (5c) ćemo u daljem tekstu nazivati benefaktivnim kauzativom/benefaktivno-kauzativnom konstrukcijom (BKK), a konstrukcije kao u primeru (5d) benefaktivnom konstrukcijom (BK).

Na svim primerima se uočava određeni stepen kako formalnog, tako i semantičkog preklapanja. Strukturno se objekatski konstituent može naći i pre i posle participa perfekta (up. primer 5b), što neretko igra ulogu u tumačenju značenja iskaza. Konstrukcije sa vezanim finitnim i infinitnim oblikom glagola se uvek mogu tumačiti kao rezultativna konstrukciju, i u njoj particip perfekta i objekat ne mogu menjati mesto:

a. Vi fikk sendt boka. 'Uspeli smo da pošaljemo knjigu'

b. Han fikk reparert bilen. 'Uspeo je da popravi auto'

4 On u navedenom članku iznosi niz kriterijuma na osnovu kojih bi ova dva slučaja trebalo posmatrati kao dve različite instance glagola få: priroda subjekata koje licenciraju (agentivni:benefaktivni), mogućnost obrazovanja imperativa, te činjenica da aktivno $f a ̊$ dozvoljava neprelazni glagol, dok pasivno $f a ̊$ zahteva tranzitivne glagole.

5 U norveškim gramatikama se termin recipijentski pasiv slabije upotrebljava, ali su prepoznati slučajevi kada se na mestu subjekta pasivne rečenice nalazi izvorni indirektni objekat: De serverte hjemmebrent til oss $\rightarrow \underline{\text { Vi }}$ ble servert hjemmebrent.

6 U Faarlund et al. (1997:849) se smatra da u ovim konstrukcijama nije nužno tumačiti få kao pomoćni glagol jer on i kao glavni glagol svom subjektu dodeljuje ulogu recipijensa: De fikk mat ('Dobili su hranu'). Up. i Lødrup (1996:80-81) za diskusiju o tome da li pasivno $f a ̊$ treba tumačiti kao pomoćni glagol. 
Ipak, činjenica da su rezultativne konstrukcije uvek sa vezanim finitnim $\mathrm{i}$ infinitnim delom predikata ne podrazumeva da ih ne možemo tumačiti i drugačije. S jedne strane se konstrukcije s odvojenim finitnim i infinitnim oblikom neće nikada tumačiti kao rezultativne: ${ }^{7}$

a. Vi fikk boka sendt. 'Poslata nam je knjiga'

b. Han fikk bilen reparert.'Popravio je auto/Dao je auto na popravku'

Primer (7a) se interpretira kao recipijentska konstrukcija, dok se $\mathrm{u}$ primeru (7b) ostvaruje benefaktivno-kauzativna konstrukcija. S druge strane, postoji i veliki broj slučajeva značenjski dvosmislenih konstrukcija što neretko predstavlja svojevrsni izazov u usvajanju ovih konstrukcija kod govornika kojima je norveški jezik L2, up. i:

- aspektualno/benefaktivno tumačenje: Han fikk reparert bilen. 'Uspeo je da popravi auto'/ 'Dao je auto na popravku'

- benefaktivno-kauzativno/recipijentsko tumačenje: Jeg fikk brevet oversendt. 'Dao sam da se pošalje pismo'/'Poslato mi je pismo'

- benefaktivno-kauzativno/benefaktivno tumačenje: Han fikk huset ødelagt. 'Dao je da se poruši kuća'/'Uništena mu je kuća'

\section{Semantičke karakteristike $f \stackrel{\circ}{\circ}$-pasiva kao benefaktivnog kauzativa}

Benefaktivno-kauzativne konstrukcije su semantički analitičke (pretpostavlja se prisustvo dva učesnika), iako kauzant nije ekspliciran formalno, te se pretpostavlja i njegova semantička perifernost (up. i termin causeeless constructions kod Loewenthal, 2003). Tako je u primerima:

$7 \quad$ Faarlund et al. (1997) ovakve konstrukcije konsekventno tumače kao odnos objekta i obaveznog objekatskog predikativa (fast objektspredikativ), analogno primerima Han fikk gulvet rent / Han fikk kroken løs. Odnos objekta i njegovog predikativa se uvek može iskazati rečenicom sa kopulativnim glagolom i subjekatskim predikativom, gde je subjekat objekat ishodišne rečenice: Dette gjorde meg sint $\rightarrow$ Jeg ble sint / Han fikk gulvet rent $\rightarrow$ Gulvet er rent / Han fikk bilen reparert $\rightarrow$ Bilen ble reparert. U slučajevima transformisanih konstrukcija sa $f a ̈-$ pasivom vezu subjekatskog predikativa i kopulativnog glagola možemo tumačiti i kao regularnu pasivnu konstrukciju (up. i Lånet ble innvilget). 
(8) a. Ser fram til å få klippet håret mitt i morgen. 'Radujem se što ću se sutra šišati'

b. Det er Verdens synsdag - få sjekket synet ditt! 'Danas je svetski dan vida - proverite svoj vid'

c. I dag fikk vi vaksinert og chippet valpene. 'Danas smo vakcinisali i čipovali štence'

očigledno da učesnik na mestu subjekta nije samostalno izvršio radnju šišanja, provere vida, vakcinisanja i čipovanja, već su to za njega obavili neki drugi učesnici - frizer, oftalmolog ili veterinar. Izostavljanje kauzanta se najčešće tumači kao zavisno od semantike glagolske lekseme, odnosno interpretacija kauzanta je ,...iscrpljena informacijama koje su date predikatom rezultata..." (Verhagen \& Kemmer, 1997: 63), te se uz glagol čipovati pretpostavlja kauzant-veterinar, uz glagol šišati kauzant-frizer itd. Pošto se tip učesnika podrazumeva, izostavljanje kauzanta kao pravog sprovodnika radnje se može tumačiti i kao konceptualno i pragmatičko defokusiranje, čime kauzant postaje i kauzalno transparentan. Uočavamo, dakle, da se u onoj meri u kojoj se uopšte i pojavljuje u literaturi, izostavljanje kauzanta u ovim slučajevima tumači kao izostavljanje konceptualno suvišne i na osnovu semantike glagola i šireg pragmatičkog diskursa predvidive komponente. Valjalo bi, smatramo, razmisliti i o sledećem: kauzanti ovih konstrukcija se mogu svrstati u agentivniji tip kauzanta jer nisu pogođeni radnjom. U regularnoj analitičkoj kauzativnoj konstrukciji je kauzator-inicijator prototipični neaficirani agens, te u semantičkoj i formalnoj hijerarhiji nadjačava kauzanta koji mu je podređen i barem delimično aficiran, a prisustvo i identitet kauzanta pokazuju rast pažnje koja se pridaje posrednom agensu. Rast pažnje se (up. Talmy, 2000: 275) može ilustrovati sledećim primerima:

(9) a. Jeg vaksinerte hunden min i dag. 'Danas sam vakcinisao psa' b. Jeg fikk hunden vaksinert $i$ dag. 'Dao sam da se pas danas vakciniše' c. Jeg fikk veterinceren til å vaksinere hunden (min) $i$ dag. 'Ubedio sam veterinara da (mi) danas vakciniše psa'

U primeru (9a) je situacija konceptualizovana samo sa agensom, bez posrednog učesnika; u primeru (9b) je posredni učesnik prisutan seman- 
tički, ali ne i identifikovan; u primeru (9c) je posredni učesnik prisutan i identifikovan i formalno i značenjski (up. srpski ekvivalent Veterinar mi je danas vakcinisao psa, u kom je stvarni agens-realizator $\mathrm{u}$ fokusu i zauzima mesto subjekta). U BKK se, osim toga, pojavljuje i pasivna dopuna u obliku participa perfekta, čime se redosled pažnje fokusira na pacijensa koji trpi radnju (kosa, vid, štenci) ${ }^{8}$ i on se kodira na mestu direktnog objekta. Ako se pretpostavi da je agensu-inicijatoru pridružena komponenta benefaktivnosti, što ga čini aficiranim agensom, postavlja se pitanje gde u hijerarhiji uloga u konstrukciji sa slabim agensom i fokusiranim pacijensom ima mesta za neki drugi tip agensa ${ }^{9}$ Moguć odgovor se nalazi u tome što se kauzant i u recipijentskim (10a) i u benefaktivnim (10c) i benefaktivno-kauzativnim (10b) tumačenjima 'fă-pasiva' može pojaviti u obliku agentivne odredbe sa predlogom $a v$ ('od (strane)...'), dakle, na samom formalnom i semantičkom kraju hijerarhije, što još jednom potvrđuje njegovo defokusiranje: ${ }^{10}$

\section{a. Bildet av denne stuen var et av fotografiene hun fikk} oversendt av svindleren på epost. 'Slika ove sobe bila je jedna od fotografija koju joj je na mejl poslao prevarant' ${ }^{\prime 1}$

8 Valja podsetiti na to da se u regularnim analitičkim konstrukcijama (tranzitivni tip) pacijens nalazi najniže u hijerarhiji, iza agensa na mestu subjekta i kauzanta na mestu direktnog objekta (up. Han fikk meg til å legge barnet).

9 Ovo bi bilo delimično u skladu sa Dowty (1991), koji u svom Principu selekcije argumenata (Argument Selection Principle) iznosi mišljenje da argument sa najviše proto-pacijentivnih svojstava teži da bude kodiran kao DO; u rečenicama gde je predikat subordiniranog događaja neprelazan, taj argument je kauzant. U rečnicama gde je predikat subordiniranog događaja prelazan, kauzant manje liči na proto-pacijensa od već prisutnog pacijensa subordinirane radnje, i prema njemu se tipično ne realizuje kao DO. Kemmer \& Verhagen (1994:122) napominju da jezici sveta kauzantu tipično ostavljaju poslednju nezauzetu poziciju u hijerarhiji, što se u norveškom jeziku ne očituje. Ipak, u ovim konstrukcijama, koje prema njima formalno i kognitivno nalikuju na regularne ditranzitivne rečenice sa IO u dativu ili instrumentalu, kauzant se kodira prema njihovom principu kao i IO - na periferiji, u ovom slučaju kao dopuna.

10 Lødrup (1996:86), polazeći od forme, objašnjava da se logički subjekat subordiniranog događaja ne pojavljuje zato što je glagol u pasivu, ali je upravo zbog toga moguća agentivna dopuna.

11 Recipijentska konstrukcija dozvoljava i dopunu sa fra ('od'): Statens helsetilsyn fikk saken oversendt fra Fylkesmannen i Rogaland ('Državnom organu za zdravstveni nadzor je ovaj slučaj poslala kancelarija guvernera iz Rogalanda'). 
b. 18-åring fikk operert inn silikonpupper av pappa.'

Osamnaestogodišnjakinji otac ugradio silikonske grudi'

c. Hun fikk odelagt ansiktet av en sjimpanse. 'Šimpanza joj je unakazio lice'

Uloge beneficijensa i maleficijensa smatraju se aficiranim ulogama, jer je cilj benefaktivnih konstrukcija da ukažu na učesnika koji je povoljno ili nepovoljno pogođen radnjom. Kittilä \& Zúñiga (2010: 4) smatraju da se obe ove uloge mogu posmatrati kao deo jedne makrouloge koja bi se mogla nazvati aficijens (affectee). Ovom gledištu je srodna su i razmatranja Radetzky \& Smith (2010: 98) koje upravo zbog aficiranosti učesnika posmatraju beneficijensa kao argument tipa proživljavača (undergoer), i to voljnih proživljavača (up. i Næss, 2007: 90-91), pod koje možemo podvesti uloge recipijensa, doživljavača i beneficijensa. Kroslingvistički podaci pokazuju da beneficijens najčešče nije ni agens ni primarni cilj događaja iz kog izvlači korist $^{12}$, i za razliku od srodne uloge recipijensa tipično je periferan učesnik, koji se stoga često i kodira kao odredba na formalnoj periferiji, na primer: Han bakte en kake for meg ${ }^{13}$ ('Ispekao mi je kolač').

Nakon analize primera koji ilustruju norveški $f a ̊$-pasiv uočavamo da zajednička semantička komponenta učesnika na poziciji subjekta nije voljnost, već aficiranost. Odnos BK i BKK pokazuje da je aficiranost (ovde protumačena kao benefaktivnost) konstantna komponenta, pri čemu se nanovo može ustanoviti kontinuum interpretacija od najmanje do najviše aficiranog učesnika, sa obrnuto proporcionalnim stepenom agentivnog učešća.

12 Kittilä \& Zúñiga (2010) napominju da benefaktivne konstrukcije opisuju heterogene događaje, pri čemu beneficijens obično profitira od toga što ne mora sam da izvrši događaj, a da neki jezici ne dozvoljavaju da agens bude beneficijens u istoj rečenici.

13 Konceptualna srodnost recipijensa i beneficijensa se odražava i na formalnom planu - u mnogim jezicima se ova dva učesnika kodiraju isto ili veoma slično, kao što je slučaj sa dativom u srpskom jeziku. U norveškom jeziku se mogu iskazati u obliku indirektnog objekta (Han gav meg boka:Han bakte meg en kake) ili periferno, u obliku predloške fraze (Han gav boka til meg: Han bakte en kake for meg). Norveški jezik pomoću povratnog determinativa frekventno kodira u vidu indirektnog objekta ličnu korist koju agens ima od radnje,: De har skaffet seg ny bil ('Nabavili su nov auto'), Jeg har kjøpt meg en jakke ('Kupila sam jaknu') ili Jeg spiser meg en brødskive ('Poješću sendvič'). 
4.1 Potpuno aficirani učesnik na poziciji subjekta

Najaficiraniji učesnik se javlja u BK, jer je na poziciji subjekta rečenice aficirani učesnik sa komponentom benefaktivnosti kao jedinom komponentom. On nije inicijator radnje, niti je odvijanje radnje pod njegovom kontrolom:

(11) a. Han fikk slått inn skallen. 'Razbili su mu glavu' b. Gjestene fikk odelagt kloer som ble levert til vask.' Gostima je uništena odeća koju su odneli na pranje'

Činjenica da se radnja konceptualizuje kao događaj van kontrole subjekta ([-voljnost], [-iniciranje]) podrazumeva da se ovako kodiraju i slučajni događaji, i tada je okolnost koja je dovela do toga tipično eksplicirana u obliku zavisne vremenske rečenice, na primer:

$$
\begin{aligned}
& \text { Han fikk knust kneskåla da han gled på beltet på } \\
& \text { gravemaskinen. 'Slomio je koleno kada se okliznuo } \\
& \text { na gusenicu bagera' }
\end{aligned}
$$

Pošto učesnik na poziciji subjekta ne inicira i ne kontroliše radnju, ne realizuje se nužno komponenta animatnosti, i u našem materijalu su veoma frekventni slučajevi kada radnju trpi neprototipični agentivni učesnik (životinja) ili kakav neživ entitet:
a. Politets hunder skal nå få trukket ut alle tenner.' Policijskim psima će sada biti izvađeni svi zubi'
b. To biler har fått knust vinduer. 'Dvama automobilima su polomljeni prozori'

Uočeno je da se BK u velikoj meri preklapaju sa onim slučajevima koje Faarlund et al. (1997: 849) nazivaju posesivom na mestu subjekta (norv. possessivledd). Uticaj na beneficijensa se vrši putem odnosa deo-celina ${ }^{14}$, tako što radnja zahvata delove (tela) beneficijensa ili neki njegov posed (up. i dalje):

14 Lødrup (2009) posvećuje dosta pažnje diskusiji o tome da li je ovde reč o partitivnosti ili posesivnosti. 
(14) a. Han fikk odelagt et øye $i$ en arbeidsulykke. 'U nesreći na radu mu je stradalo oko'

b. "BT" fikk knust dekket av bølge! '[Jedrilici] "BT" je talas smrskao palubu'

c. En bileier fikk knust ruta. 'Vlasniku automobila je razbijen prozor'

Za razliku od BKK, gde je agentivna dopuna moguća ali nije frekventna, u BK se uzročnik veoma često specifikuje u vidu klasične agentivne dopune sa predlogom $a v$, upravo zbog toga što subjekat konstrukcije nije uzročnik radnje. Na toj poziciji se registruje čitav spektar manje ili više tipičnih kauzatora, kao što su prototipični agens (15a), prrodna sila (15b), eventivni kauzatori (15c), sredstvo ili instrument (15d-e):
a. Han fikk odelagt bilen av en sint mann. 'Besan čovek mu je uništio auto'
b. Han fikk odelagt båthavnen sin av stormen Sandy.
'Oluja Sendi mu je uništila marinu'
c. Han fikk ødelagt nattesøvnen av festingen. 'Proslava mu je uništila san'
d. Hun fikk ansiktet odelagt av syre. 'Kiselina joj je uništila lice'
e. Han fikk kjeven knust av sjampanjeflaske. 'Flaša šampanjca mu je razbila vilicu'

Ovom podtipu pripadaju i sve instance recipijentske interpretacije 'få-pasiva'.

4.2 Aficirani i agentivni učesnik na poziciji subjekta

U BKK se na poziciji subjekta javlja učesnik koji istovremeno kodira i agentivnost i benefaktivnost. Tumačenje nekih primera kontekstualno je uslovljeno, pa neretko nailazimo na dvosmislene rečenice. U rečenici:

(16) Per fikk bilen reparert. 'Per je popravio auto', 
Per se tradicionalno tumači i kao agens i beneficijens. On je agens radnje odvoženja kola na popravku/izdavanja naloga, ali su kola popravljena u njegovu korist od strane nerealizovanog kauzanta, uz mogućnost agentivne odredbe: av en mekaniker ('od strane automehaničara') ili priloške odredbe za mesto: på et lokalt verksted ('u lokalnom servisu'). I mehaničar i lokalni servis pretpostavljaju prisustvo nemarkiranog kauzanta. S druge strane se ova ista rečenica može protumačiti i kao BK, gde je Per samo beneficijens izvršene radnje, bez njenog iniciranja: neko je bez njegovog znanja popravio kola u njegovu korist, a kontekst se može testirati dodavanjem agentivne odredbe av sin kone ('od strane (svoje) žene'). Agentivne odredbe su daleko frekventnije ukoliko je subjekat rečenice samo beneficijens jer ne postoji koreferentnost između agensa i beneficijensa.

Iako Faarlund et al. (1997:849) izdvajaju posesivne odnose u posebnu podgrupu i smatraju ih ključnima za razlikovanje tipova subjekata u konstrukciji sa 'få-pasivom', uočavamo da se, iako semantički bitni, javljaju u više konstelacija. Posesivni odnosi se javljaju i u BKK, i to prvenstveno konceptualizovani kao deo čovečijeg tela ili čovekovo vlasništvo:
a. Jeg fikk trukket ut en tann. 'Izvadio sam zub/Izvađen mi je zub'
b. Hun fikk undersøkt øynene. 'Pregledala je oči/Pregledali su joj oči'
c. Hva koster det å få renset en brudekjole? 'Koliko košta hemijsko čišćenje venčanice?‘

Tako se na poziciji subjekta, za razliku od BK, javljaju samo prototipični agensi jer samo oni mogu imati nameru da se radnja sprovede, $\mathrm{i}$ tako je iniciraju (up. primer 13a, u kom se policijski psi nikako ne mogu tumačiti kao inicijatori radnje). Postoje, doduše, neke glagolske lekseme koje zahtevaju protoipičnog agentivnog učesnika i u takvim slučajevima se pod uobičajenim okolnostima ne ostavlja konceptualni prostor za nekog drugog učesnika koji bi bio vršilac radnje, te se takve konstrukcije pre tumače kao rezultativni 'få-pasiv' nego kao BKK. Ispitali smo slučajeve na leksemama føde ('roditi') i mate ('hraniti'), koje tumačimo kao slučajeve dvopersonalnih kauzativa ${ }^{15}$. Materijal je pokazao da se u skoro svim slu-

15 Pod dvopersonalnim kauzativima podrazumevamo inače sasvim retke slučajeve kodiranja dvoaktantske strukture pomoću sintetičkih, a ne analitičkih kauzativnih konstrukcija. 
čajevima veze fikk født i fikk matet moraju tumačiti kao postignuće: uspela je da rodi, stigla je da rodi, imala je prilike da hrani. Jedan jedini slučaj sa konstrukcijom fikk født se može protumačiti kao BKK:

(18) Saken om kvinnen som fikk fodt to guttebarn for snart ett år siden har utviklet seg til å bli et mareritt. 'Slučaj žene kojoj su pre skoro godinu dana rođena dva dečaka postao je prava noćna mora'

Rečenica se tumači kao BKK na osnovu konteksta u kom je eksplicirano da je reč o surogat majci koja je navedenoj ženi rodila blizance (ved hjelp av surrogatmor fra India 'uz pomoć surogat majke iz Indije').

\subsection{Agentivni i neaficirani/parcijalno aficirani} učesnik na poziciji subjekta

Treći podtip čine konstrukcije u kojima se na poziciji subjekta pojavljuje učesnik isključivo agentivnog tipa i nije pogođen radnjom čiji je inicijator, ili se može smatrati da je samo parcijalno aficiran. U prvu kategoriju ubrajamo slučajeve rezultativne upotrebe 'få-pasiva', a u drugu neke instance BKK, primarno one slučajeve koji se mogu protumačiti kao parcijalna aficiranost putem posesivnog odnosa. Pri tome kauzant kao stvarni realizator radnje i dalje ostaje semantički impliciran, a kauzator je agens-inicijator za koga se ne može sa sigurnošću postulirati stepen aficiranosti:
a. I dag fikk jeg trukket den siste hjørnetannen på sheltien min. ${ }^{16}$ 'Danas sam svom šetlandskom ovčaru izvadila poslednji kutnjak'
b. Hva betaler du for å få klippet håret til barnet ditt?'
Koliko plaćate da se vašem detetu ošiša kosa?'

16 U norveškom jeziku se posesivnost može iskazati na više načina: genitivom ili gentivskim izrazom (Lines hode, Line sitt hode), posesivnim determinativom (hennes hode, hodet hennes), te predloškom frazom (hodet til Line). Osim toga, za delove tela je tipična konstrukcija sa predlogom på ('na') kojom se detaljno bavi Lødrup (2009): hodet på henne. Tako i ovde: hjørnetannen på sheltien. 
Sličnost sa BKK je u tome što konstrukcija kodira i agensa i beneficijensa, koji se može konceptualizovati kao vlasništvo agensa ili makar kao entitet koji od njega zavisi (up. posesive sheltien min, barnet ditt). Ipak, ovde je reč o dvostepenom posesivnom odnosu, pri kom radnja zapravo pogađa deo tela beneficijensa, koji nije koreferentan s kauzatorom (za razliku od primera $17 \mathrm{a}-\mathrm{c}$ ).

\section{Zaključak}

Norveški få-pasiv je u jednom od svojih značenja tipičan i dosledan formalni način kodiranja benefaktivne kauzacije, budući da su drugi načini formalnog izražavanja (kontekstualni kauzativi, permisivne konstrukcije sa la kauzativni refleksiv) nepredvidivi i/ili neproduktivni. Analizom prikazanog dolazi se do zaključka da semantika $f a$-pasiva nije heterogena u onoj meri kako to predstavlja tradicionalna gramatička literatura, već da se preko hibridnog benefaktivno-kauzativnog tumačenja na kontinuumu srodnih interpretacija mogu povezati i ostale interpretacije, primarno preko zajedničkih komponenti (1) neekspliciranog agensa-realizatora, i (2) manje prototipičnog agensa-inicijatora. Ustanovili smo da je neeksplicirani kauzant konstantno obeležje, dok se aficiranost učesnika na poziciji subjekta može prototipski gradirati od neagentivnog učesnika koji potpuno trpi radnju, preko benefaktivno-kauzativnog aficiranog kauzatora, sve do agentivnog učesnika koji je samo parcijalno aficiran. Ustanovljeno je, takođe, da su posesivni odnosi, koji u norveškoj gramatičkoj literaturi čine jednu izolovanu semantičku podgrupu $f a$-pasiva zapravo prisutni u svim utvrđenim semantičkim realizacijama ove konstrukcije.

\section{Citirana literatura}

Babby, L.(1993). Hybrid causative constructions: Benefactive causative and adversity passive. In B. Comrie \& M. Polinsky (eds.), Causatives and Transitivity (pp. 343-367). Amsterdam/Philadelphia:John Benjamins Publishing Company.

Faarlund, J. T., Lie, S., \& Vannebo, K. I. (1997). Norsk referansegrammatikk. Oslo: Universitetsforlaget. 
Frawley, W. (1992). Linguistic Semantics. New Jersey/London: Lawrence Erlbaum Associates.

Kemmer, S. \& Verhagen, A. (1994). The grammar of causatives and the conceptual structure of events. Cognitive Linguistics, 5 (2), 115-156.

Kittilä, S. \& Zúñiga, F. (2010). Benefaction and malefaction from a crosslinguistic perspective. In F. Zúñiga \& S. Kittilä (eds.), Benefactives and malefactives: typological perspectives and case studies (pp.1-28). Amsterdam, Philadelphia: John Benjamins Publishing Company.

Loewenthal, J. (2003): Meaning and use of causeeless causative constructions with laten in Dutch. In A. Verhagen \& J. van de Weijer (eds.), Usage-Based Approaches to Dutch. Lexicon, grammar, discourse (pp. 97-129). Utrecht: LOT.

Lødrup, H. (1996). The Theory of Complex Predicates and the Norwegian Verb få 'get'. Working Papers in Scandinavian Syntax, 57, 76-91.

Lødrup, H. (2009). External and Internal Possessors with Body Part Nouns: The Case of Norwegian. SKY Journal of Linguistics, 22, 221-250.

Næss, Å. (2007). Prototypical Transitivity. Amsterdam/Philadelphia:John Benjamins Publishing Company.

Pylkkänen, L. (2000). Deriving Adversity. In R. Billerey \& B.D. Lillehaugen (eds.), WCCFL 19 Proceedings (pp. 399-410). Somerville, MA: Cascadilla Press.

Radetzky, P. \& Smith, T. (2010). An areal and cross-linguistic study of benefactive and malefactive constructions. In F. Zúñiga \& S. Kittilä (eds.), Benefactives and malefactives: typological perspectives and case studies (pp. 97-120). Amsterdam, Philadelphia: John Benjamins Publishing Company.

Rawoens, G. (2007). Kausativa verbkonstruktioner i svenskan och nederländskan. En korpusbaserad syntaktisk-semantisk undersökning (doktorska disertacija). Universiteit Gent.

Shibatani, M. \& Pardeshi, P. (2001): The Causative Continuum. In M. Shibatani (ed.), The Grammar of Causation and Interpersonal Manipulation (pp. 85-126). Amsterdam, Philadelphia: John Benjamins Publishing Company.

Talmy, L. (2000). Toward a cognitive semantics. Vol. I: Concept Structuring Systems. Cambridge, MA: MIT Press.

Verhagen, A. \& Kemmer, S. (1997). Interaction and causation: Causative constructions in modern standard Dutch. Journal of Pragmatics, 27, 61-82. 
Sofija Bilandžija

\section{Summary}

\section{BENEFACTIVE CAUSATIVE AND NORWEGIAN $F A$-PASSIVE}

This paper deals with benefactive causative, a subtype of indirect causation, which presuposes a mediated causative event with two participants, i.e. a causer who instigates the action and a causee that carries out the action of the embedded predicate until the goal/result is reached. The crucial differences lie in the fact that the benefactive causative leaves the semantically implied causee role formally unexpressed, which formally portrays the two-participant event as one-participant event. Secondly, the agentivity of the causer role is reduced not only by the the fact that the causer is percieved only as the instigator and not the effector of the whole causative event (mediacy), but crucually by a benefactive component being added. The author analyses the semantics of the benefactive causation in correlation with the typical and consequent way of expressing this

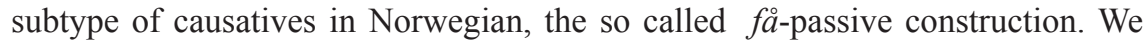
show that different semantic interpretations of the $f a$-passive are not as heterogeneous as usually perceived, but form a semantic continuum of purely benefactive, benefactive-causative or causative interpretations, which show that the participant coded as syntactic sybject can be totally or partially affected by the process. 